\title{
Survival after Renal Transplantation in Man: An Interim Report on 54 Consecutive Transplants*
}

\author{
R. Y. CALNE, M.S., F.R.C.S. ; D. B. EVANS, M.B., B.CH., M.R.C.P. ; B. M. HERBERTSON, M.D., M.C.PATH. \\ V. JOYSEY, B.SC., PH.D. ; R. MCMILLAN, M.B., CH.B., D.oBST.R.C.o.G.; R. R. MAGINN, M.D., F.A.C.S. \\ P. R. MILLARD, M.B., B.S.; J. R. PENA, M.D.; J. R. SALAMAN, M.B., B.CHIR., F.R.C.s. \\ H. J. O. WHITE, M.CHIR., F.R.C.S. ; J. F. R. WITHYCOMBE, M.CHIR., F.R.C.s.; D. E. YOFFA, F.R.A.c.s.
}

Brit. med. F., 1968, 2, 404-406

Early experience with cadaveric renal transplantation was disappointing. In a series of 20 cases only three patients were able to leave hospital and return to their normal occupations (Calne et al., 1966). In the past three years, however, results have improved. Straffon et al. (1965), Mowbray et al. (1965), Hume et al. (1966), and Kincaid-Smith et al. (1967) reported on their experience over the preceding two years, in which 20 patients out of 24 with cadaveric renal transplants were surviving with function in the grafted kidneys. Five out of seven survivals were more than one year and 11 out of 16 more than six months after operation. Our report is concerned with 54 consecutive renal transplants in 49 patients, $^{1}$ five of whom received two kidneys ; 51 transplants were from cadavers and three from parental living donors.

\section{Materials and Methods}

Recipients.-The ages of the recipients ranged between 17 and 53 years, the average being 33 . Thirty-four were males. All patients were in terminal stages of chronic renal failure, the cause of which was glomerulonephritis in 27, pyelonephritis in 13, polycystic kidneys in 5, gout in 1, hypoplastic kidneys in 1 , malignant hypertension in 1 , and bilateral renal artery stenosis in 1. Malignant hypertension was a significant feature in 37 .

Donors.-The ages of the donors ranged from 10 to 72 years, the average being 45 years. Thirty-eight were males. There were three live parental donors, aged 46, 58, and 71 years. The causes of death in the cadaver donors were head injury in 15 , myocardial infarction in 13, cerebral tumour or haemorrhage in 10 , pulmonary embolus in 1 , and spontaneous rupture of the aorta in 1. Both kidneys were utilized from 11 cadavers.

\section{Preoperative Management}

Patients were admitted to a special transplantation and dialysis unit which occupies the whole of a top floor. There are 10 single-bedded rooms and one haemodialysis room. Most patients were haemodialysed twice weekly by means of a Kiil dialyser with single passage of dialysis fluid and ultrafiltration. In circumstances where dialysis space was limited, or if there were no remaining sites for insertion of Scribner shunts, then peritoneal dialysis was performed. Hypertension was controlled by dialysis, salt and water restriction, and hypotensive drugs. If difficulty was experienced in producing a safe blood pressure then the patients' diseased kidneys were removed. Other indications for bilateral nephrectomy were infection of the renal tract and huge polycystic kidneys. Bilateral nephrectomy was performed on 11 patients before or at the time of renal transplantation. Efforts were made to eliminate pathogenic organ-

* From Addenbrooke's Hospital, Cambridge.

1 The first patient in this series is our longest survivor. His case history was recorded in a previous report-Case 2 of Calne et al. (1966). isms from patients and staff by regular bacteriological studies and appropriate treatment with local or systemic chemotherapy. No attempt was made to raise the haemoglobin levels to normal, and patients were transfused as little as possible to maintain a haemoglobin of around $9 \mathrm{~g} . / 100 \mathrm{ml}$., a level which enabled them to withstand surgery satisfactorily. Six units of blood were kept closs-matched for patients awaiting surgery.

\section{Tissue Typing}

A 24-hour tissue-typing service became available after the thirtieth transplant. Lymphocytes from subsequent patients were tested against a panel of cytotoxic sera from multiparous women. The results were compared retrospectively with those obtained from most of the cadaver donors and prospectively from the parental donors. ABO red blood cell groups were determined in all donors and recipients, and in no case was a kidney from an $\mathrm{A}, \mathrm{AB}$, or $\mathrm{B}$ donor transplanted into a recipient with incompatible red cell antibodies.

\section{Donor Selection}

In view of the severe difficulties experienced in obtaining donor kidneys, donors less than ideal were often utilized, resulting in a high incidence of postoperative tubular necrosis in the transplants. Postoperative haemodialysis was required in all but eight of the recipients of cadaver kidneys, but not in the recipients of live donor kidneys. With the exception of primary intracerebral tumours, no donor suffered from malignant disease. The other criteria of donor selection were deaths uncomplicated by renal tract infection, hypertension, or septicaemia. Though kidneys from young donors were preferred, the ages of nine donors were between 60 and 72 years.

\section{Technique}

The technique has been described in detail elsewhere (Calne, 1965).

Cadaver Donors.-As soon after death as possible the kidneys were removed under full sterile precautions, and blood was taken for tissue typing and red cell grouping. The interval between death of the donor and revascularization of the transplant varied between 45 and 395 minutes, with an average of 166 minutes. The periods during which the kidneys were not adequately protected by cold-that is, warm ischaemia time made up of the interval between death and cooling plus the time for the anastomoses-ranged from 26 to 133 minutes, with an average of 83 minutes. The times for the anastomoses ranged from 13 to 38 minutes, with an average of 20 minutes.

Live Donors.-The patients were assessed medically and intravenous pyelography and arteriography were performed to ensure that both kidneys were normal and to determine the anatomy of the arterial supply of the kidneys. The most suit- 
able kidney was removed via a loin incision, the operation being synchronous with that of the recipient.

Kidney Preparation.-After removal the kidneys were immediately immersed in normal saline at $4^{\circ} \mathrm{C}$. In most cases the renal artery was cannulated and the kidney perfused by gravity at $1.5 \mathrm{~m}$. of water pressure with $200 \mathrm{ml}$. of Ringer's solution at $4^{\circ} \mathrm{C}$. containing $12.5 \mathrm{~g}$. of human albumin per litre and 2,000 units of heparin per litre. Ampicillin and carbenicillin were added to the perfusate in some cases.

Recipient Operation.-Via a suprainguinal incision, the iliac vessels were exposed in the extraperitoneal plane. In most cases the left kidney was transplanted to the right iliac fossa or vice versa. The renal artery was anastomosed end-to-end to the internal iliac artery and the renal vein end-to-side to the external iliac vein. In cases with multiple renal arteries a Carrel patch of aorta was taken and anastomosed end-to-side to the external iliac artery. When this was done the transplant was usually placed in the homolateral iliac fossa so that the renal vein did not cross the renal arteries. The ureter was implanted into the bladder via a submucous tunnel. In two patients receiving second transplants, in which there had previously been pelvic sepsis, the pelvis of the transplanted kidney was anastomosed to the patient's own ureter. The capsule of the kidney was divided longitudinally along the renal convexity from pole to pole.

\section{Immunosuppression}

Azathioprine and prednisone or prednisolone were the main immunosuppressive agents. The dosage regimen is shown in Table I. Any impairment of renal function, tachycardia, hypertension, pyrexia, or renal swelling or tenderness, unless otherwise explained, was considered to represent a rejection crisis. Treatment of rejection involved a massive increase in steroids, and in some cases actinomycin C, extracorporeal irradiation (Maginn and Bullimore, 1968), or antilymphocyte globulin ${ }^{2}$ were added.

\begin{tabular}{|c|c|c|c|}
\hline \multirow{2}{*}{$\ldots \ldots$} & \multicolumn{3}{|c|}{ TABLB I.-Immunosuppression } \\
\hline & $\begin{array}{l}\text { Immediate } \\
\text { Transplant } \\
\text { Function }\end{array}$ & $\begin{array}{l}\text { Ischaemic } \\
\text { Tubular } \\
\text { Necrosis }\end{array}$ & Rejection Crisis \\
\hline $\begin{array}{c}\text { Azathioprine } \\
\text { (mg./kg.) }\end{array}$ & 5 for 2 days, & $\begin{array}{l}5 \text { for } 1 \text { day, then } 1 \\
\text { daily untildiuresis, } \\
\text { when increased to } \\
2.5 \text { daily }\end{array}$ & Maximum tolerated dose \\
\hline $\begin{array}{l}\text { Prednisolone } \\
\text { (mg.) }\end{array}$ & \multicolumn{2}{|c|}{$\begin{array}{l}100 \text { for } 2 \text { days, falling by } 25 \text { every } 2 \text { days } \\
\text { until } 50 \mathrm{mg} .50 \mathrm{mg} \text { continued for } \\
30 \text { days, then dose reduced by } 5 \mathrm{mg} \text {. } \\
\text { every } 30 \text { days }\end{array}$} & $\begin{array}{l}200 \text { for } 3 \text { days, reducing } \\
\text { by } 25 \text { every } 3 \text { days } \\
\text { until } 50 \text { mg. reached } \\
\text { Actinomycin C } 200 \mu \mathrm{g} . \\
\text { daily for } 3 \text { days, } \\
\text { or anti-lymphocyte glo- } \\
\text { bulin or extracorporeal } \\
\text { irradiation of blood }\end{array}$ \\
\hline
\end{tabular}

The aim of the drug management was to lower the steroid dosage to a minimum as soon as possible and to give a maximum tolerated dose of azathioprine. Sudden major changes in drug dosage in the absence of rejection crises were avoided.

\section{Postoperative Management}

The patients were barrier-nursed for 10 days or until the wound stitches and catheter were removed. They were, however, allowed up on the first postoperative day or as soon as they were sufficiently fit. Biochemical examination of the blood and urine was performed six days a week until the patient was on a stable immunosuppressive dosage with satisfactory renal function. Estimations were then performed on alternate days until the patient was discharged from hospital.

- Kindly provided by Professor M. F. A. Woodruff and Dr. K. James.
The patients at first had weekly and then fortnightly follow-up visits. An attempt was made to see all patients every three months in Cambridge, but one patient refused to come and six live abroad. If inexorable rejection occurred in spite of maximal immunosuppressive therapy the transplant was removed and the patient returned to intermittent dialysis for a minimum of 40 days (Hume et al., 1966), when a second transplant was considered. The most satisfactory cases were discharged from hospital within six weeks of surgery, but the average postoperative period in hospital was nine weeks, with a range of six weeks to four and a half months. The average time spent awaiting transplantation was six weeks, with a range of one day to six months.

\section{Results}

Of the 54 consecutive transplants there were at the time of writing 33 functioning kidneys (60\%) and 34 of the 49 patients transplanted were alive $(70 \%)$. Seventeen of the 27 (63\%) patients transplanted more than one year ago were alive and 17 of the $29(59 \%)$ transplants were functioning. Six of seven patients transplanted more than 22 months ago have functioning kidney grafts. The longest period of survival is two and a half years. This case has been reported (Calne et al., 1966).

Fifteen of the 49 recipients have died; six patients had their transplants removed and five of these received second transplants. Since no kidney functioning at four months has subsequently failed, the results of the 44 cadaver transplants performed more than four months ago are considered more fully (Table II). The cases transplanted during the last four months are too early to assess. The three patients receiving kidneys from their parents are a separate category-two are alive and well at three months and two weeks respectively with good transplant function; one died from fulminating haemorrhagic varicella at four weeks.

TABLB II.-44 Transplants in 42 Patients With a Follow-up of Four Months or More

\begin{tabular}{ll|c|c}
\hline & Functioning Transplants & Living Patients \\
\hline At 4 months &. & 25 of $44(58 \%)$ & 28 of $42(67 \%)$ \\
At 1 year & $:$ & 17 of $29(59 \%)$ & 17 of $27(63 \%)$ \\
At 22 months & $\because$. & 6 of $7(86 \%)$ & 6 of $7(86 \%)$ \\
\hline
\end{tabular}

\section{Cadaver Transplants Performed in 42 Patients with a Follow-up of 4 Months or More}

Four months after operation 25 of the $44(58 \%)$ cadaveric transplants were functioning. Nineteen transplants failed-the causes of failure are shown in Table III. Four deaths occurred from infection transferred from the donors who had developed bronchopneumonia while being artificially respired before death Twenty-eight of the $42(67 \%)$ patients were alive and two received two transplants. The 25 patients with functioning

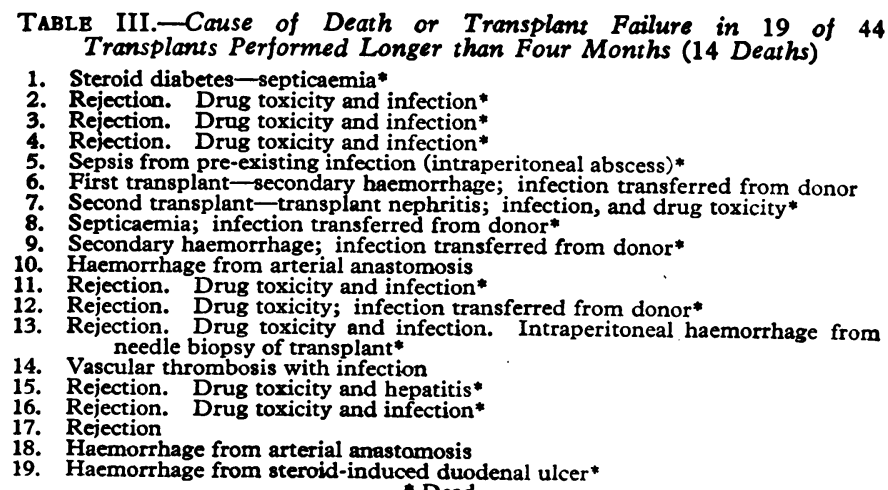


transplants at four months subsequently had little evidence of rejection. Eight $(32 \%)$ had no clinical or biochemical evidence of rejection at any time. Three had rejection crises between four and 12 months after operation which were successfully treated. In most cases the transplant function has slowly improved. The average blood urea level was $60 \mathrm{mg} . / 100$ ml., with a range of $27-150 \mathrm{mg} . / 100 \mathrm{ml}$., serum creatinine 1.8 $\mathrm{mg} . / 100 \mathrm{ml}$, with a range of $0.9-3 \mathrm{mg} . / 100 \mathrm{ml}$., and creatinine clearance $58 \mathrm{ml} . / \mathrm{min}$., with a range of $20-120 \mathrm{ml} . / 100 \mathrm{ml}$. Twenty-four patients have been restored to normal activity: the majority have returned to their previous jobs; the most active patient operates a bulldozer. One patient lives a restricted life due to steroid arthropathy and probable chronic rejection of the transplant.

As soon as the transplants function adequately the patients develop a sense of well-being which is in excess of the euphoria due to steroids. They develop voracious appetites and often say that they feel "cleaner" than when they were on dialysis.

The complications developing in our patients were numerous and bizarre. They will be the subject of another communication. The correlation of clinical results with tissue typing will also be reported separately. The most obvious difficulty has been the management of rejection. The independent value of actinomycin C, extracorporeal irradiation, and antilymphocyte globulin were impossible to assess, since all rejection crises were also treated with massive doses of steroids. During the course of this series of cases policy has changed. Instead of pursuing immunosuppression to life-threatening toxicity, a kidney with inexorable rejection is now removed and immunosuppression stopped.

\section{Discussion}

Though the maximum follow-up period is only two and a half years, the satisfactory quality of life of the majority of our patients has convinced us that cadaveric renal transplantation is valuable therapy. Our patients do not require convincing; most had suffered severe symptoms of uraemia often complicated by hypertension, heart failure, peripheral neuritis, and pericarditis. To be restored from such a moribund condition to a normal life is worth while even if the ultimate prognosis is uncertain. The pressure on dialysis beds and the shortage of cadaver donors caused us to embark on a limited programme of live donor transplants from close blood relatives who insisted on giving a kidney. We feel that it is unjustifiable to refuse to perform a transplant under these circumstances when the alternative is death. There have been 20 deaths on the waiting-list in the past two years due to inadequate facilities for dialysis in the referring hospitals. This figure, however, means little in the context of the 2,000-3,000 deaths per annum from uraemia in the United Kingdom in patients between the ages of 5 and 55 . Unfortunately, at present the dialysis and transplant centres in the United Kingdom can treat only a small fraction of these cases.

\section{Summary}

Fifty-four consecutive renal transplants in 49 patients are reported. There were 51 cadaver and 3 live donors. At the time of writing $33(60 \%)$ of transplants were functioning and 34 patients $(70 \%)$ were alive. All transplant failures had occurred within four months of operation. Seventeen of the $29(59 \%)$ transplants were functioning at one year and six of the seven transplants performed more than 22 months ago continued to function. The longest period of survival is two and a half years since operation.

We wish to acknowledge the help we have had from our medical and nursing colleagues and in particular the nursing staff of the renal unit. We are grateful to the John Bonnett Clinical Laboratories for the numerous biochemical, haematological, and bacteriological studies they have performed on our patients. We thank the referring physicians for their collaboration both preoperatively and in the postoperative follow-up period.

\section{REFERENCES}

Calne, R. Y. (1965). Brit. f. Urol., 37, 285

Calne, R. Y., Loughridge, L., MacGillivray, J. B., and Swales, J. D. (1966). Brit. med. $7 ., 2,1345$.

Hume, D. M., et al. (1966). Ann. Surg., 164, 352.

Kincaid-Smith, P., et al. (1967). Lancet, 2, 59.

Maginn, R. R., and Bullimore, J. A. (1968).' Brit. 7. Radiol., 41, 127

Mowbray, J. F., et al. (1965). Brit. med. F., 2, 1387.

Straffon, R. A., Nakamoto, S., and Kolf, W. J. (1965). Brit. F. Urol., 37, 370 .

\section{Preliminary Communications}

\section{Body Height and Imipramine Side-effects}

\section{Brit. med.F., 1968, 2, 406-407}

Genetically determined variations in metabolism are of importance in determining the steady-state blood concentrations of some drugs. Variability in the population depends on polymorphisms of enzymes involved in the metabolism of a drug and may influence both clinical effectiveness and toxicity (Price Evans, 1965 ; Hammer et al., 1967 ; Moody et al., 1967).

A genetic polymorphism in drug metabolism may be suspected when blood levels seem to be influenced by sex (Gillette, 1963 ; Moody et al., 1967) or racial differences (Motulsky, 1957), or show a discontinuous variability (Price Evans, 1962), or show an association with a genetically determined disorder such as Down's syndrome (Turpin et al., 1967).

A well-known example of genetic polymorphism is that which determines that all persons are either rapid or slow acety- lators of the drugs isoniazid, sulphadimidine, hydrallazine (Price Evans and White, 1964), and probably phenelzine (Price Evans et al., 1965).

The steady-state plasma levels of depressed patients on a standard dosage of tricyclic antidepressants have been shown to have markedly bimodal frequency distributions (Hammer and Sjöqvist, 1967); this suggests the existence of a genetic polymorphism for the metabolism of these drugs. Patients complaining of side-effects while on this group of antidepressants are those with high steady-state plasma levels (Hammer et al., 1967).

It seems possible that genes controlling drug plasma levels may also have an influence on physique. In this study a retrospective investigation has been made of the physique of patients who complained of side-effects while on imipramine therapy.

\section{METHOD}

Over a period of three years 93 patients with sustained depression in my general practice were considered for admission to a 